\title{
Guidelines for policy modellers - 30 years on: New tricks or old dogs?
}

\author{
$\underline{\text { G.J.Syme }}^{a}$, D. Bennett ${ }^{b}$, D.K. Macpherson c, and J.F. Thomas ${ }^{d}$ \\ ${ }^{a}$ Edith Cowan University, Joondalup, WA, Australia, ${ }^{b}$ Retired Albany, WA, Australia, , ${ }^{c}$ Retired, Sydney, \\ NSW, Australia, ${ }^{d}$ Curtin University of Technology, Fremantle, WA, Australia \\ Email: g.syme@ecu.edu.au
}

\begin{abstract}
Systems thinking and the use of modelling to assist in natural resources decision making started in the early 1960's (Forrester, 1961). In the early 1970's a multidisciplinary program was established in CSIRO's Division of Land Resources Management to, among other issues, research and develop models to assist in the resolution of persistent and multi-faceted environmental issues. The authors of this paper were members of that group.

We recently decided to look at what has been learned about these reasonably intractable problems over the more than 30 years period since. If it is true that the half life of modelling papers is around eight years and, apparently, decreasing (Haggett, 2005), then we can expect that the wheel has often been reinvented. So we describe issues as they were expressed up to the early 1980's and compare and contrast them with concerns after the turn of the century in two contexts - the development of systems thinking in modelling and deciding when and how to model.
\end{abstract}

Three general criticisms of systems analysis were evident then: (1) the models were highly mathematical and therefore opaque to the user, and it was hard even for 'experts' to explain unexpected findings; (2) welfare, as expressed by economic or utilitarian criteria, was considered to be poorly represented in systems practice (systems thinking was being viewed here as rational, while it was slowly being recognized that apparently irrational behaviour is an important part of the social fabric and could not be ignored (Glazer, 1978)); (3) the systems approach relied on lists derived from planners, but in the absence of "systems thinking" guidelines they were only lists of what planners thought of doing, not comprehensive in any strong sense. These three major drawbacks still exist and in much the same form today.

Development of systems thinking is now much more widespread. The applications gap does not appear to be filled, though there have been attempts to broaden the client base by participative model construction to reach a consensus of what is agreeable to most stakeholders.

"Irrational behaviour" still threatens systems analysis and comes in several forms. There is lack of acceptance that utilitarian criteria should be used to drive the solution. And the consequences of implementing a model's solution may lead to unforeseen consequences and behaviours by and to affected parties.

Very few papers have been written in recent years on guidelines on when to model and when not to do so. There seems to be no connection with earlier publications. The field does not appear to have progressed. We perceive a world in which those who can, model, and those who can't still feel little need to try. It is to be hoped that interest in the issues of when and why to model will not wane. It would be a shame, perhaps a source of conflict, if modelling remained yet another marker that separates a 'them' from an 'us'.

Some of us have now been much closer to decision-makers. Our observations include: (a) Timing is critical in decision-making. Sometimes there are a few hours for deliberation, for others decades. A modeller has to be close to help with the quick ones. Advice that comes too late will not be relevant. (b) Close contact with decision makers is essential, as is their training. (c) A contract from the client is a desirable/necessary precondition. (d) Trust, and lack of it, will always be important in accepting advice. (e) Committees, especially those charged with doing something and feel that they cannot progress without assistance, are good targets. But committees, like modelling contracts, can be solely methods of delaying decisions. (f) Modelling physical and biological systems is less contentious than using utility to guide advice.

Key Words: systems thinking, history, applications gap, guidelines, participation 


\section{INTRODUCTION}

Systems thinking and the use of modelling to assist in natural resources decision making started in the early 1960's (Forrester, 1961). In the early 1970's a multidisciplinary program was established in CSIRO's Division of Land Resources Management to, among other issues, research and develop models to assist in the resolution of persistent and multi-faceted environmental issues. The authors of this paper were members of that group.

Some modelling work was produced, which appeared to influence both farm and State Government decisions, due to strong collaborative arrangements with key personnel in State Government in Western Australia (e.g. Bennett and Thomas, 1982). But there was a concern among us that the influence of the modelling work seemed relatively modest. This concern reflected that of others (Holling, 1978) and was manifested in a number of conference papers. These examined the limitations and advantages of systems thinking in assisting "better" policy development, the evaluation of then current guidelines for constructing successful models, as well as the generation of an ex-ante decision tree for assessing when modelling was worthwhile (Macpherson and Bennett, 1981). Finally some thoughts on how to construct a successful modelling activity (Bennett and Macpherson, 1985) and how to "market" models (Syme and Bennett, 1979) were provided. The underlying concerns related to how to improve "adoption" of the models and how this adoption would improve decision making in the long term.

We recently decided to look at what has been learned over the more than 30 years period since about these reasonably intractable problems. If it is true that the half life of modelling papers is around eight years and, apparently, decreasing (Haggett, 2005), then we can expect that the wheel has often been reinvented. So we describe issues as they were expressed up to the early 1980's and compare and contrast them with concerns after the turn of the century in two contexts - the development of systems thinking in modelling and deciding when and how to model.

\section{SYSTEMS THINKING AND THE APPLICATION GAP}

\subsection{Then}

Macpherson and Bennett (1981) stated that "the systems approach was being touted ten years ago as a 'Cure for Chaos' (Ramo, 1969). ... The concept has arisen of an 'applications gap' between what the state-of-the-art promises and what decision makers will accept. The frustrations that result from the existence of this gap make it hard for analysts to accept that the systems approach is not wholly rational, and that rationality is not everything."

The systems approach was described as consisting of some or all of three elements: (1) the representation of the subject matter of planning as having many possible alternative states, having many interconnected parts, showing complex changes over time and responding to many inputs; (2) the use of economic, or at least utilitarian, criteria to guide the choice of one alternative state of the system over another, and (3) the organisation of the planning process into a supposedly comprehensive list of subtasks, often in the form of a flowchart.

Three general criticisms of systems analysis were evident then: (1) the models were highly mathematical and therefore opaque to the user, and it was hard even for 'experts' to explain unexpected findings; (2) welfare, as expressed by economic or utilitarian criteria, was considered to be poorly represented in systems practice (systems thinking was being viewed here as rational, while it was being recognized that apparently irrational behaviour is an important part of the social fabric and could not be ignored (Glazer, 1978)); (3) the systems approach relied on lists derived from planners, but in the absence of "systems thinking" guidelines they were only lists of what planners thought of doing, not comprehensive in any strong sense.

Participative or interactive modelling was developing. An example was the Interactive Structural Modelling approach of Malone (1975) whereby decision makers were encouraged to say what factors were important to their problem-the ideas were then organised by the computer into a simple model whose structure was drawn out as a flow chart for inspection. 


\subsection{Now}

It is evident that the applications gap is still of concern to many modellers (e.g. Syme et al, 2009, Vonk and Geertman, 2008). Continued funding for research and models increasingly depends on the demonstration of outcomes which usually can only be validated by the decision makers who use them.

The representation of problems as having many alternative states is now entrenched and has been reinforced with the general acceptance of scenario planning (e.g. Celino and Concilio, 2010, Erdmann and Hilty, 2010) in which options for the planning problem at hand are generated. There has been a rise of valuation techniques such as choice modelling and contingent valuation to represent the value of the environment in expressing trade-offs. Even where non-dollar valuation approaches have been employed the utilitarian philosophy has continued with the persistence of multi-attribute rating. It is even being suggested that ethical considerations should be explicitly reflected in modelling methodology (Burgenmeier, 2003).

The development of participative tools as a support for deliberative decision making has however made the definition of success for the modelling process less clear. For example, the inclusion of the wider community in environmental decision making has, in the view of Beierle and Cayford (2002), five major goals: 1 incorporating public values into decisions; 2 improving the substantive quality of decisions; 3 . resolving conflict among competing interests; 4 building trust in institutions; 5 educating and informing the public. Which matters most to the modeller? Goal 2 seems most akin to what was once the central aim of modelling: an accurate, if opaque, model. Also, even in new, participative, integrated modelling where an overall architecture has been agreed, the task is usually divided into disciplinary sub-components to ensure adequate expertise in modelling for the social, economic and environmental domains.

When the system that is so represented is put into motion on the computer, it may seem that the problem of model opacity has been reduced by the vast improvement in computer capacity in terms of speed and graphics. But these "boys' toys" may attract users, yet not lead to adequate understanding. There is a greater emphasis on participative approaches which are directed to removing this reproach and encouraging understanding. This may go as far as determining methodology; framing a problem as a Bayesian net lets the decision-maker's and expert's judgments be incorporated into the model in a way that is more direct than in a complex Forrester model - at some cost to detailed representation of physical processes.

There are still basic problems. Firstly it is difficult for even well educated people to get a feeling for how systems operate (White, 2008). Training can improve such understanding (Plate, 2010), but this is unlikely to be available to all decision makers, even those who have the time. If the model isn't understood in the way that modellers think it should be, there may be many undetected misunderstandings of the significance of the model to the decision. This relates both to the details of the system studied, but also to the specific requirements of others in the decision making system itself (Syme et al., 2009).

Secondly, even with an integrated modelling language there will be components of the model which are quite opaque to other disciplines involved. This difficulty is made worse when the relationships between components are complex, despite the attraction of having scenarios which are more holistic. The comprehension problem gets even worse if the issue of uncertainty is treated seriously by the modeller.

\subsection{What progress?}

Participation lays down the welcome mat, but what if the guests find the meal inedible? It is important to accept that the opacity problem is never likely to be fully solved. Also, the acceptance of a model's outputs is likely to depend on a context that includes (a) how the participant feels about the issue modelled and the participatory program generally; (b) the level of trust in the modeller or decision maker, (c) perceptions of acceptable risk and uncertainty and (d) the socio-political environment generally. For the modeller, and the community, these issues haven't grown easier in a climate of diminishing trust in science and government.

The trend in participative modelling is to use negotiative tools within model construction to reach a consensus of what is agreeable to most stakeholders. This practice may represent retreat towards a "satisficing" rather than an "optimising" role for modelling, and in this setting the model's calculations may have only a marginal importance as calculations, being instead a 'seed' around which arguments develop. Marginalisation of the model was something that was observed back then by Greenberger et al. (1976): "in politically delicate situations, the modeller with an explicit model may be as welcome as the proverbial bull in a china shop". This bears comparison to the situation of the IPCC today. Greenberger et al also point out that "the process of modelling can sharpen the expertise of the modeller, and this expertise, more than the model or its forecasts may influence the making of public decisions". If this is the case perhaps there should 
be only modest expectations of the use of models. What we see here is not so much the reinvention of the wheel as endless prototyping of roundish objects that don't roll.

"Irrational behaviour" remains an issue. Fulton et al. (2010) note that “ ... whilst uncertainty is broadly recognised as a pervasive feature of fisheries management to date most of the attention has focused on only part of that uncertainty -scientific uncertainty - however the uncertainty generated by unexpected resource use behaviour is critical as it has unplanned consequences." Fulton et al. hold out hope that through careful understanding of the micro-motivations of stakeholders and the use of appropriate incentives with the appropriate mix of other policy instruments behaviour can be massaged toward sustainable ends. The fat lady has not so far sung. The role of rationality in these motivations and responses to incentives remains a moot point and one that is still not discussed widely enough. The wider political framework within which application will occur on many occasions identified then by Greenberger et al. (1976) may override the influence of even carefully designed incentive structures for quite rational reasons (Pincione and Teson, 2006). To some this may be akin to process error in biological models, whereby it is acknowledged that there will be aspects of a system that will be difficult to model. In human systems however, the 'difficult to model' component may be the overwhelming factor in governing both the behaviours of individuals and their social systems.

To some extent the evaluation of quality of models internally can be done by peer review. The checklist aspects of the relationship between the clients, their problem and the model, however, have to be done case by case. It is essential to address them. If this is not done, anxiety about the applications gap will remain and the role of the modeller in policy space will remain ill defined.

\section{WHEN TO MODEL?}

\subsection{Then}

"If the decade of the 1960's was characterised among modellers by the promotion of modelling and systems methods generally as means of forecasting the future and resolving social problems (e.g., Ramo, 1969); then the decade of the 1970's was notable for documentation of the overreach that followed such enthusiasm (e.g., Hoos 1972, Brewer, 1973). The criticism of modelling has been intense, but it has by no means stopped modelling activity, especially in the areas of economic and energy policy (Greenberger et al., 1976). In urban planning, environmental management and land-use planning, the discouragement has been far greater, and modellers have tended to retreat somewhat from expecting to influence policy into investigating theoretical issues (e.g. Brotchie et al., 1980). There is also a need for filtering processes which will eliminate proposals for modelling that are not worth-while and which will guide the imagination of the modeller to attempt what is sensible" Bennett and Macpherson (1981). After examining the guidelines for modelling already offered by other authors (e.g. Biswas, 1976, Wildavsky, 1973), Bennett and Macpherson (1981) produced some guidelines in the form of a decision tree. Three sections examined (a) whether the external climate was right for potential adoption; (b) whether it was possible to construct the model without great difficulty; and (c) whether the users will be happier as a consequence. The answers to questions in the first section were thought of as highly relevant to any decision to continue. One issue in relation to the second question was the availability of quality data, This is a problem that has not been resolved by increasing sophistication in the mathematics of modelling.

\subsection{Now}

An interest in the need for guidelines for deciding when to model and how to make sure quality was maintained has reappeared in the 21 st century. For example Risbey et al. (2005) produced a checklist for quality assistance for environmental modelling which does not quote any earlier efforts at the same task. Risbey's checklist is more detailed in terms of the robustness, or internal rigour, of the model, than that of Bennett and Macpherson (1981), but less detailed in terms of many of the issues associated with bridging the application gap. Other guidelines published then did however concentrate more on internal structure. Since Risbey et al. (2005) has been cited 17 times to this point interest may be maintained. With the growth of group based participatory modelling guidelines have also been recently produced (e.g. Rouewette et al. 2002) and can, we hope, be influential.

\subsection{What progress?}

The level of modelling activity is now much greater, so something is happening. But, again, consider the IPCC and its difficulty in gaining leverage in the real world and the apparently unexpected effects of the Global Financial Crisis despite Wall Street employing 'quants' who attempted to model behaviour mathematically. Putting these straws in the wind together suggests a world in which those who can, model, 
Syme et al., Guidelines for modellers-30 years on

and those who can't still feel little need to try. Orderly bridge-building protocols seem to be at a discount, relative to the world if not to the modellers.

It is to be hoped that interest in the issues of when and why to model will not wane. It would be a shame, perhaps a source of conflict, if modelling remained yet another marker that separates a 'them' from an 'us'.

\section{DISCUSSION}

The basic characteristics of modelling have not changed dramatically over the 30 years despite improvements in computer power and simulation software. There does not seem to be an orderly development of knowledge in the applications gap literature.

Essentially the key characteristics of systems thinking of acknowledging potential alternate states of systems by scenario thinking coupled with the improvement of utility by considering the system as a dynamic whole remain. This is the case even though the Ngrams of "systems analysis" (http://ngrams.googlelabs.com/ ) suggest that the term "systems thinking" is in eclipse. The narrower utilitarian viewpoint has tended to be broadened out in participative modelling but it would be fair to say that criteria for outcomes are less precise, which on the face of it makes 'internal rigour' less important. Then, we argued (e.g. Thomas et al,, 1984) that the way out was to be more philosophically careful, using the work of philosophers such as Habermas (1975) and asserting that only the "force of the better argument as defined in rational discourse can improve decision making". While this idea has not died (e.g. Schoop (2004) for the case of negotiation support) it is far from being a commonplace.

The three major drawbacks back then still exist and in much the same form. Perhaps some modelling activities have improved in terms of the adequacy of lists with the advent of tools such as Bayesian networks. There are still issues of procedure here, with the problem of "confirmation bias" "group think" and other mishandlings of evidence known to the expert, but not to the usual modeller or to the general decision maker.

The "when to model" issue remains much as it was, but the emergence of some new checklists to help anatomise the question may revive thought in this area. While internal rigour may have improved in some ways, the theoretical understanding of the decision-making environment on the outside of the applications gap has not progressed noticeably, while the practice has been more seriously politicised.

What is the significance of all this? Thinking seriously about the applications gap is still important as modellers still need a better analysis function if they are not to continue the then situation of "analysts are content to accept that the systems approach is not a panacea, but most of them believe that their current role is too small" (Macpherson and Bennett, 1981). Our role is our choice and we need to think more carefully about it.

Some of us have now been much closer to decision-makers. Our observations, which reflect those of the authors cited earlier by Bennett and Macpherson (1981) include: (a) Timing is critical in decision-making. Sometimes there are a few hours for deliberation, for others decades. A modeller has to be close to help with the quick ones. Advice that comes too late will not be relevant. (b) Close contact with decision makers is essential, as is their training (see for example Pannell \& Roberts, 2009). (c) A contract from the client is a desirable/necessary precondition. (d) Trust, and lack of it, will always be important in accepting advice. (e) Committees, especially those charged with doing something and feel that they cannot progress without assistance, are good targets. But committees, like modelling contracts, can be solely methods of delaying decisions. (f) Modelling physical and biological systems is less contentious than using utility to guide advice.

\section{REFERENCES}

Beierle, T.C. and J. Cayford (2002). Democracy in Practice: Public participation in environmental decisions. Resources for the Future, Washington DC.

Bennett, D. and Macpherson D.K. (1981). The role of guidelines in deciding to model. In Proceedings of the 25th Annual Conference of the Australian Agricultural Economics Society (no pagination).

Bennett, D. and Macpherson D.K. (1985). Structuring a successful modelling activity. In Agricultural Systems Research for Developing Countries. Proceedings of an international workshop. J. V. Remenyl (Ed.) pp70-76. Hawkesbury Agricultural College, Richmond, NSW.

Bennett, D., and J. F. Thomas, (Eds). (1982). On Rational Grounds. Systems Analysis in Catchment Land Use Planning. Elsevier, Amsterdam.

Biswas, A.K. (1976). Mathematical Modelling and water-resources decision-making. In Biswas, A.K. (Ed.) Systems Approach to Water Management. pp. 398-414, McGraw-Hill, New York.

Brewer, G.D. (1973). Politicians, bureaucrats and the consultant. Basic Books, New York. 
Syme et al., Guidelines for modellers-30 years on

Brotchie, J.F., Dickey, J.W. and Sharpe, R. (1980). TOPAZ - general planning technique and its Application at the regional, urban, and facility planning levels. Springer-Verlag, Berlin

Burgenmeier, B. (2003). Modelling equity: A debate about values. Environmental Modelling and Assessment, 8,165-174.

Celino, A. and Concilio G. (2010). Participation in environmental spatial planning: Structuring-scenario to manage knowledge in action. Futures, 42, 733-742.

Erdmann, L. and Hilty L.M. (2010). Scenario Analysis: Exploring the macroeconomic impacts of information and communication technologies on greenhouse gas emissions. Journal of Industrial Ecology, 14 (5), 826-843.

Forrester, J.W. (1961). Industrial Dynamics. MIT Press, Cambridge MA.

Fulton, E.A., A.D.M. Smith, D.C. Smith, and I. E. van Putten. (2010). Human behaviour: the key source of uncertainty in fisheries management. Fish and Fisheries, 12 (2), 189-208.

Glazer, N. (1978). Superstition and Public Policy. Regional Studies 12: 619-628.

Greenberger, M., Crenson, M.A. and Crissey, B.L. (1976). Models in the policy process. Russell Sage Foundation, New York.

Habermas, J. (1975). Legitimation Crisis. Beacon Books, Boston.

Haggett, P. (2005). Postscript: continuity and change in spatial modelling. Journal of Geographical Systems, 7 (3) 403-408.

Holling, C.S. (1978). (Ed) Adaptive Environmental Assessment and Management. pp121-122. Wiley, Chichester.

Hoos, I.R. (1972). Systems analysis in public policy. A critique. University of California Press, Berkeley.

Macpherson, D.K. and Bennett D. (1981). Strengths and weaknesses of the systems approach. In Land use recent advances. pp 39-48. UWA Extension, Perth.

Malone, D.W. (1975). An introduction to the application of interceptive structural modelling. Proceedings of the IEEE 63: 397-404.

Pannell, D.J. and Roberts, A.M. (2009). Conducting and delivering integrated research to influence land-use policy: salinity policy in Australia, Environmental Science and Policy 12(8): 1088-1099

Pincione, G. and Teson F. (2006). Rational Choice and Democratic Deliberation. A theory of discourse failure. Cambridge University Press.

Plate, R. (2010). Assessing individuals'understanding of nonlinear causal structures in complex systems. Systems Dynamics Review, 26 (1), 19-33.

Ramo, J. (1969). Cure for Chaos. Fresh Solutions to Social Problems through the Systems Approach. David McKay Company Inc., New York.

Risbey, J., van der Sluijs, J., Kloprogge, P., Ravetz, J., Funtowicz S. and Quintana S.C. (2005). Application of a checklist for quality assistance in environmental modelling to an energy model. Environmental Modelling and Assessment, 10, 63-79.

Rouwette, E.A.J.A., Vennix, J.A.M. and van Mullekom T. (2002). Group model building effectiveness: a review of assessment studies. Systems Dynamics Review, 18 (1) 5-45.

Schoop, M. (2004). The Worlds of Negotiation. In: M. Aakhus, and M. Lind (eds.). Proceedings of the 9th International Working Conference on the Language-Action Perspective on Communication Modelling (LAP 2004). 179-196. http://csrc.lse.ac.uk/asp/aspecis/20050034.pdf

Syme, G.J. and Bennett D. (1979). Bridging the operations research - applications gap in agriculture. Proceedings of the 4th National Conference, Australian Society for Operations Research. pp.331-59. (Australian Society for Operations Research Incorporated: Melbourne.)

Syme, G.J., Dambacher J.M., Dzidic P.L., Fulton E.A., and Boschetti F. (2009). Integrating research, modelling and decision making: A network and knowledge processing approach for sustainable development of a coral reef. In Anderssen, R.S., R.D. Braddock and L.T.H. Newman (Eds) $18^{\text {th }}$ IMACS Congress and MODSIM09 International Congress on Modelling and Simulation. Modelling and Simulation Society of Australia and International Association for Mathematics and Computers in Simulation, July 2009, pp2915-2921. ISBN : 978-0-9758400-7-8. http:mssanz/org/au/mod

Thomas, J.F., Bennett, D. and Macpherson, D.K. (1984). Theory and practice in catchment management land use planning: The Murray Valley of West Australia. In Conservation and the Economy Conference, Sydney, 1984. AGPS/Dept of Arts Heritage and the Environment.

Vonk, G. and S. Geertman. (2008) Improving the adoption and use of planning support systems in practice. Applied Spatial Analysis, 1, 153-173.

White, P. A. (2008). Beliefs about interactions between factors in the natural environment. Applied Cognitive Psychology, 22,559-572.

Wildavsky, A. (1973). 'Consumer Report'. Science, 182, 1335-7. 